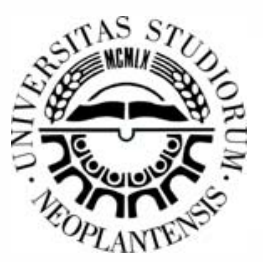

\title{
Microstructural Analysis of Inconel 625 Nickel Alloy / UNS S31803 Duplex Stainless-Steel Dissimilar Weldments
}

\author{
Tuba Karahan ${ }^{a}$, Tolga Mert ${ }^{b}$, Mustafa Tümer', Zaim Mithat Kerimak \\ a İstanbul Gedik University, 34876 Kartal/Istanbul, Turkey \\ b Yıldız Technical University, 34349 Beşiktaş/İstanbul, Turkey \\ c Kocaeli University, 41180 Kartepe / Kocaeli, Turkey \\ d Anadolu Casting Co, 51780 Körfez / Kocaeli, Turkey
}

\begin{abstract}
In this study, Inconel 625 nickel alloy and UNS 31803 duplex stainless steel (DSS) dissimilar pairs were welded with MIG welding process. Weld metal, obtained with ERNiCrMo-3 filler wire, was subjected to mechanical and microstructural investigations. Notch impact test and micro hardness measurements were realized on weld metal in order to evaluate 31803 mechanical properties. Microstructural changes in fusion line of the base metals were examined using optical and electron microscopes. Phase precipitations rich of Ti and Mo elements were detected among dendritic austenite arms in the weld metal. It was observed that ERNiCrMo-3 filler metal had sufficient toughness because of high nickel content.
\end{abstract}

Key words: Inconel, duplex stainless steel, toughness, hardness, microstructure

\section{INTRODUCTION}

Ni-base alloys are one of the most important engineering materials by means of being used both at cryogenic temperatures and temperatures approaching $1200^{\circ} \mathrm{C}$ $\left(2190^{\circ} \mathrm{F}\right)$ because the matrix of the solid solution alloys remains austenitic (face - centered cubic structure that is the predominant phase in $\mathrm{Ni}$ - base alloys) from solidification to absolute zero, and also their welding consumables offer some properties in as-welded condition that no other family of welding products can provide [1]. Dissimilar metal welding is one of the challenging and exciting fields of research which has several economic and engineering profits in many areas [2, 3]. Dissimilar welding between Ni-based superalloys and duplex stainless steels has many technical advantages and involves wage cost savings in terms of reducing the selection of very expensive materials $[4,5]$.

Ni-based alloys are more expensive than stainless steels, and duplex stainless steels become more admirable and reliable candidate for replacement when compared to austenitic and ferritic stainless steels [3]

Preferability of Ni-based alloys comes of their excellent characteristics such as; suitable yield, good tensile and creep strength and perfect corrosion resistance [2-3]. Duplex stainless steel is a less expensive material which brought down the cost without concession of the efficiency [6].

Dissimilar welds of Ni-based alloys and duplex stainless steels have substantial advantages in geothermal power plants, aeronautical, aerospace, chemical, off-shore and marine applications, steam generators, reformer and pyrolysis tubes in oil refineries. In addition, these dissimilar welds are used in sensitive industries for heavy duty operations such as petrochemical factories, acid production plants and nuclear power plants, where a combination of the high mechanical strength and high corrosion resistance is required [1-6].

Dissimilar welding of Ni-based super alloys with stainless steel has some difficulties such as ductility-dip cracking (which occurs during the multi-pass welding of Inconel 625), hydrogen cracking (cold cracks) and brittle phases in the fusion and heat affected zone of the weld which may lead to poor mechanical and metallurgical characteristics [7]. Due to these reasons; selecting the right proper filler wire is one of the most important subjects to be taken into consideration not to face solidification cracking, HAZ liquation cracking and HAZ 
unmixed zone and formation of secondary phases. Following the studies regarding MIG welding of Inconel 625 nickel alloy and UNS 32205 duplex stainless-steel dissimilar pairs, Sridhar et al. [7] observed that reliable(successful) joint with a significant impact toughness had been achieved by ERNiCrMo-3 filler metal [8].

\section{EXPERIMENTAL PROCEDURE}

Inconel 625 and duplex stainless steel (DSS) base metals with $5 \mathrm{~mm}$ thicknesses were utilized in the experiments. ERNiCrMo-3 (AWS A5.14) filler wire with $1.2 \mathrm{~mm}$ diameter was used to join dissimilar Inconel 625 and DSS using metal inert gas (MIG) welding. Chemical compositions of base metals and filler wire were acquired with Foundry Master Pro optical emission spectrometry device and they are given in Table 1. Shielding gas supplied was $100 \%$ Argon with a flow rate of 20 L.min-1. After welding, three specimens for Charpy V-notch impact test were machined from welded coupons as well as one specimen for hardness test and one for microstructural evaluation. Vickers hardness test was employed with $200 \mathrm{~g}$ load for 10 seconds. Microstructure specimen was ground and polished and then electro etched at $10.4 \mathrm{~V}$ in $\mathrm{HCl}$ and $\mathrm{HNO}$ solution (3:1 ratio). JEOL JSM-6060LV scanning electron microscope (SEM) was utilized to analyze microstructures

Table 1-Chemical composition of base metals and wire (wt.\%)

\begin{tabular}{ccccccc}
\hline Base/Wire & $\boldsymbol{C r}$ & $\boldsymbol{N i}$ & $\boldsymbol{M o}$ & $\boldsymbol{T i}$ & $\boldsymbol{N b}$ & $\boldsymbol{F e}$ \\
\hline Inconel 625 & 20,8 & 61,6 & 9,05 & 0,18 & 3,45 & 4,17 \\
UNS S31803 & 22,2 & 5,5 & 2,91 & 0,01 & 0,03 & 66,5 \\
ERNiCrMo-3 & 22 & Balance & 9 & -- & 3,5 & 1 \\
\hline
\end{tabular}

\section{RESULTS ANDDISCUSSIONS}

\subsection{Microstructure}

Microstructures of Inconel 625 and UNS 32205 base metals are given in Fig 1. Except for segregations, texture after solidification is entirely austenite because of high nickel content. Austenite islands in ferrite matrix oriented along rolling direction are observed in UNS 32205 duplex stainless-steel microstructure. It is clear austenite islands are interconnected and comprised of equiaxed grains. Figure 2 shows microstructures of face, middle and root of weld metal. Columnar dendrites are present in cap zone, which solidifies last. In the middle of weld metal, columnar structure transformed to columnar and equiaxed dendrites because of the tempering effect of upper passes. This tempering effect is most visible in root pass and texture is entirely cellular. Multipass welding of totally austenitic weld metal changed the solidification form and this situation affects weld metal toughness after joining of austenitic base metal, which has extremely high toughness.
Fusion line and HAZ of dissimilar weld metals are given in Fig 3. Fig 3a shows Inconel 625 HAZ microstructure. There is a dendritic structure at the fusion line towards the main material and a nucleated structure along the grain boundaries. Subsequently, the structure towards the weld metal is generally composed of columnar dendrites that have been formed in different axes.

Changes within HAZ of UNS S31803 are given in Fig 3b. Transition zone between HAZ and fusion line was formed during solidification as a result of diffusion of different elements. This zone has different elemental compositions because of the intermixture of base metal and filler metal, and it represents the increment of elemental Fe.
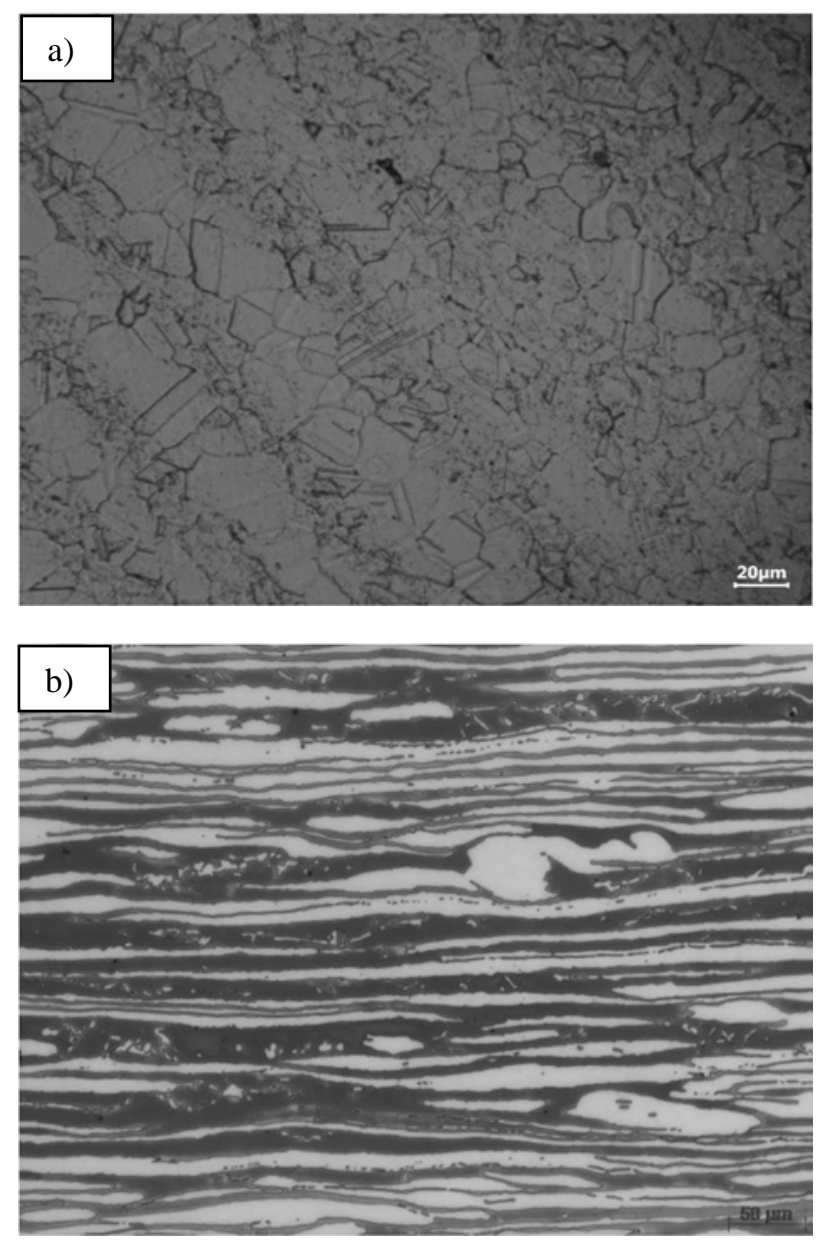

Fig. 1 Base metal microstructure a) Inconel 625 b) UNS 32205

\subsection{Toughness and Fracture Surfaces}

Charpy V-notch impact tests were performed to specimens extracted from weld metal and HAZs of Inconel 625 and DSS dissimilar weldments using ErNiCrMo-3 filler wire at room temperature. Results are given in Fig 4. Weld metal had mean impact energy of $109 \mathrm{~J} \pm 6$ owing to high nickel content and austenitic texture. Mean impact energy values obtained from specimens machined from HAZs of Inconel 625 and UNS S31803 were $146 \mathrm{~J} \pm 13$ and $92 \mathrm{~J} \pm 9$, respectively. Impact energy values of DSS HAZ were $37 \%$ and $16 \%$ less than those of Inconel HAZ and weld metal, respectively. 
Fractographs gathered at $3000 \mathrm{X}$ magnification using SEM, after impact tests applied to WM and HAZ specimens are given in Figure 5. Ductile web structure is observed in weld metal (Fig 5a). Since there are less orientation observed, UNS S31803 HAZ (Fig 5b) is believed to represent base metal. In this region, pit depths increased, and sharp edges of surfaces and an inclusion were spotted.
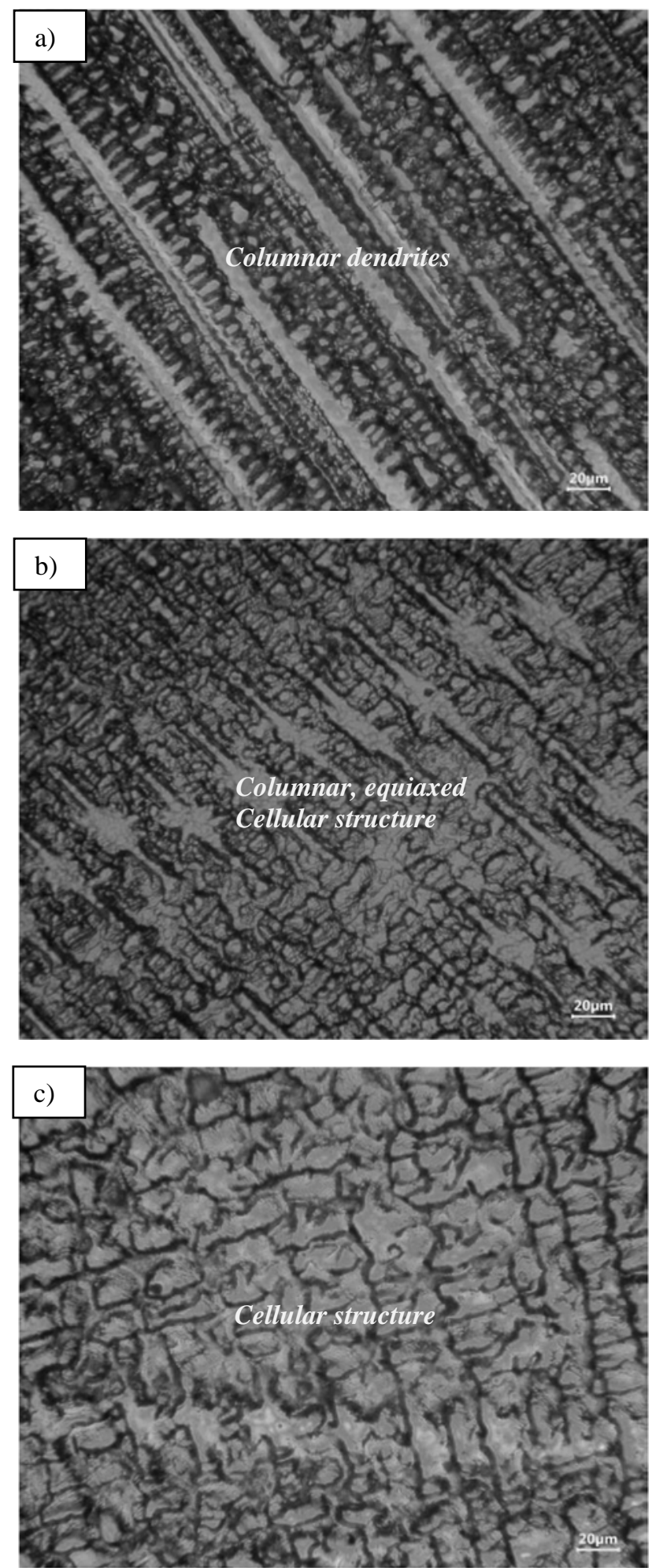

Fig 2 Weld metal microstructures a) Face b) Middle c) Root
Elemental analysis of inclusion in DSS HAZ is given in Table 2. It is believed inclusion is an intermetallic phase which was formed as A2B (A: Cr, Fe, Ni / B: Nb, Ti, $\mathrm{Mo}$ ). Since intermetallic phases are brittle, it is accredited the inclusion detected is responsible for the drop of toughness in DSS HAZ. Fig 5c presents Inconel 625 HAZ to fusion line (FL) transition.

Elongated web-like structure and ductile pits within the base metal indicates the fracture surface of the weld metal diverged from the smaller grains. This zone has the highest toughness.

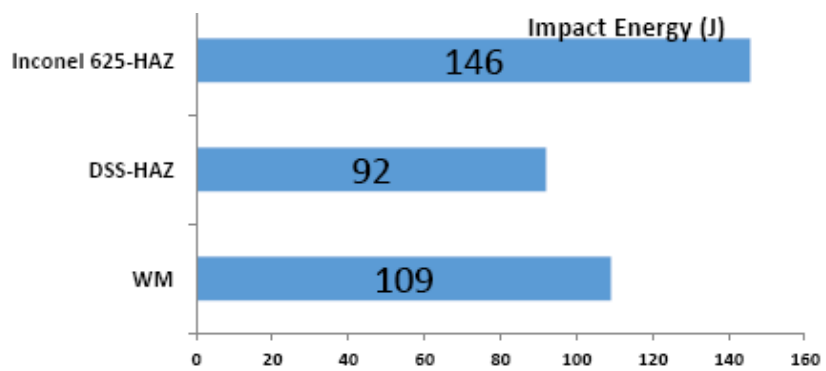

Fig 3. HAZ microstructures a) Inconel 625 b) UNS S31803
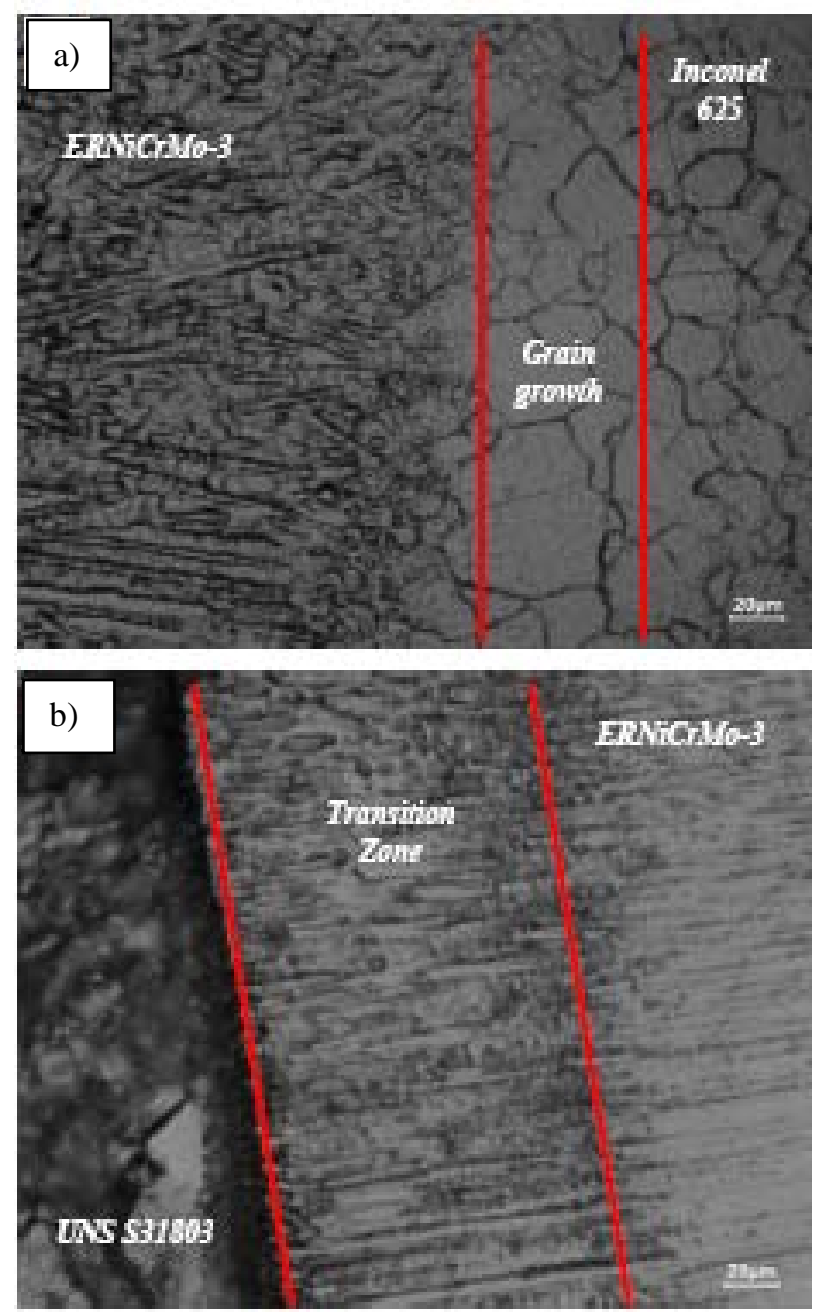

Fig 4. Toughness values 

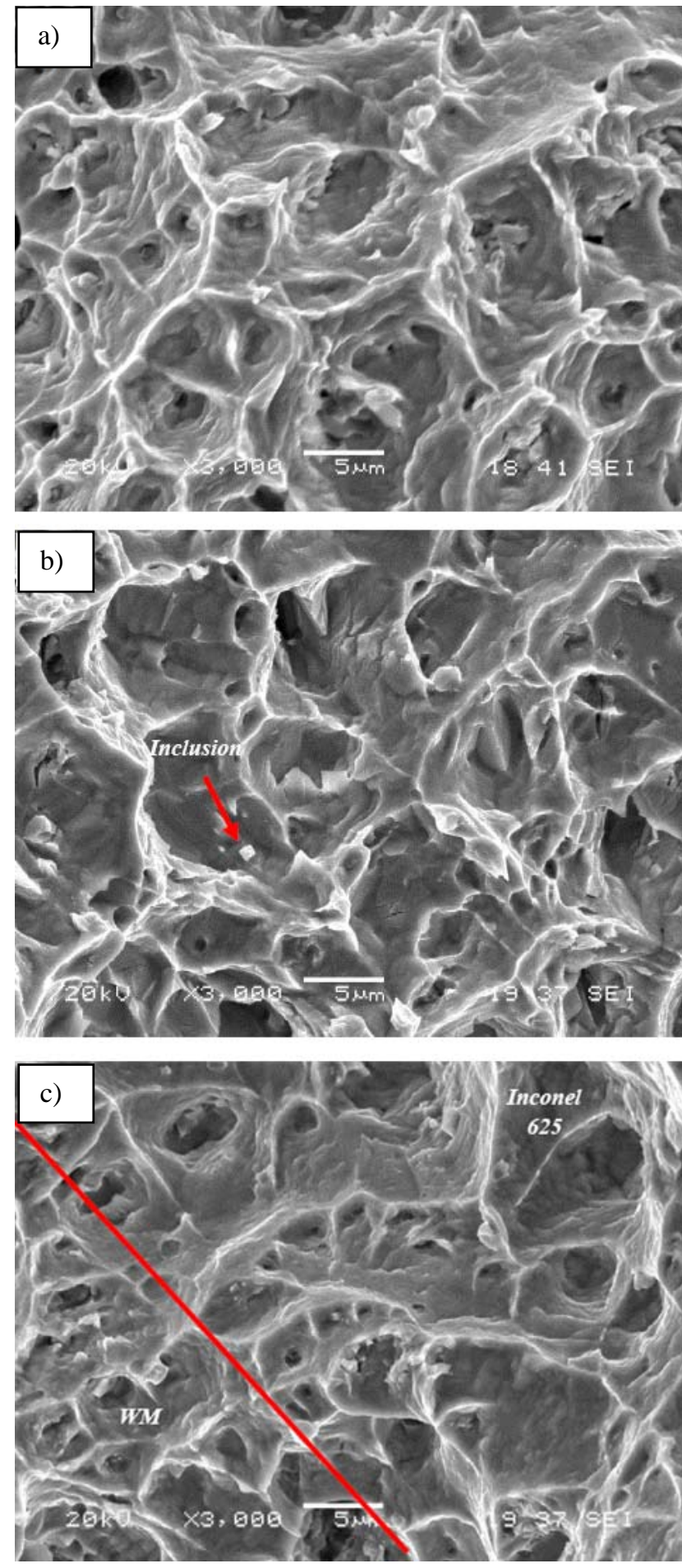

Fig 5. a) WM b) DSS HAZ c) Inconel HAZ

Table 2 - Elemental analysis of inclusion in DSS HAZ

\begin{tabular}{cc}
\hline Element & $\boldsymbol{w t . \%}$ \\
\hline $\mathrm{O}$ & 1.861 \\
$\mathrm{Ti}$ & 3.042 \\
$\mathrm{Cr}$ & 19.818 \\
$\mathrm{Fe}$ & 19.681 \\
$\mathrm{Ni}$ & 34.293 \\
$\mathrm{Nb}$ & 12.314 \\
$\mathrm{Mo}$ & 8.992 \\
\hline
\end{tabular}

Vickers hardness measurements taken along a line including base metal, HAZ, FL and WM zones are given in Fig 6. Similar elemental contents of Inconel 625 base metal and ERNiCrMO-3 filler metal yield to similar hardness profiles. Highest hardness value at weld metal is $258 \mathrm{HV} 0.2$. Hardness reaches to $289 \mathrm{HV} 0.2$ at HAZ of UNS S31803 base metal because of ferrite formation.

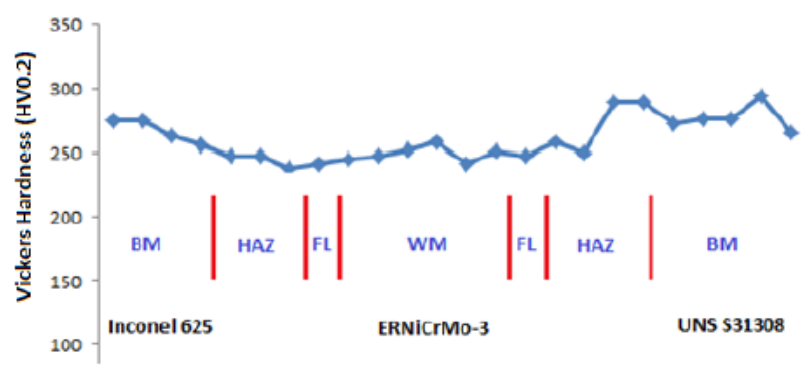

Figure 6 Vickers hardness profile of weldment

\section{CONCLUSION}

- $\quad$ The fusion and HAZ zone occurred by welding austenitic Inconel 625 nickel alloy and the austenitic-ferritic UNS 31803 duplex stainlesssteel material pair with the ERNiCrMo-3 filler wire, provide adequate mechanical properties.

- Microstructural features will be fully austenitic because of the elemental content of filler wire ERNiCrMo-3. However, repetitive thermal effects have effectuated different solidification facets and microstructural forms.

- When it is examined with regard to toughness 146J and Inconel 625-HAZ zone has the highest toughness value. There is a decrease of $54 \mathrm{~J}$ in terms of toughness at the HAZ zone of UNS 31803. It is evaluated that the intermetallic phases formed near this region cause this condition. Weld metal has sufficient toughness with $109 \mathrm{~J}$.

- In general, hardness values of the weld metal and the base metal are very similar to each other.

\section{ACKNOMFDGEMENTS}

Authors would like to thank Gedik Welding Co. for providing filler metals.

\section{REFERENCES}

[1.] J. DuPont N., J. Lippold C., and S. Kiser D., Welding Metallurgy and Weldabilidy of Nickel Based Alloys. 2000.

[2.] K. D. Ramkumar et al., "Influence of laser peening on the tensile strength and impact toughness of dissimilar welds of Inconel 625 and UNS S32205,” Mater. Sci. Eng. A, vol. 676, pp. 88-99, 2016. 
[3.] J. Kangazian and M. Shamanian, "Mechanical and microstructural evaluation of SAF 2507 and incoloy 825 dissimilar welds,” J. Manuf. Process., vol. 26, pp. 407-418, 2017.

[4.] K. D. Ramkumar et al., "Studies on the weldability, microstructure and mechanical properties of activated flux TIG weldments of Inconel 718," Mater. Sci. Eng. A, vol. 639, pp. 234-244, 2015. J. Kangazian, M. Shamanian, and A. Ashrafi, "Dissimilar welding between SAF 2507 stainless steel and Incoloy $825 \mathrm{Ni}$ - based alloy: The role of microstructure on corrosion behavior of the weld metals,” J. Manuf. Process., vol. 29, pp. 376-388, 2017.
[5.] K. D. Ramkumar et al., "Investigations on the structure - Property relationships of electron beam welded Inconel 625 and UNS 32205,” J. Mater., vol. 68, pp. 158-166, 2015.

[6.] R. Sridhar, K. Devendranath Ramkumar, and N. Arivazhagan, "Characterization of microstructure, strength, and toughness of dissimilar weldments of inconel 625 and duplex stainless steel SAF 2205," Acta Metall. Sin. (English Lett., vol. 27, no. 6, pp. 1018-1030, 2014.

[7.] J. Kangazian and M. Shamanian, "Characterization of Structure- Property Relationship of Incoloy 825 and SAF 2507 Dissimilar Welds,” Trans. Indian Inst. Met., vol. 71, no. 7, pp. 1747-1757, 2018. 